\title{
The design of index system of irregularities considering the whole process of electricity market transaction
}

\author{
WANG Haining ${ }^{1,2}$, LIU Dunnan ${ }^{3}, \quad$ HU Huiwen ${ }^{3}$, ZHANG Xiaochun ${ }^{3}, \quad$ YANG Mo ${ }^{3}, \quad$ YANG Ting ${ }^{3}, \quad$ SHI Shuhong ${ }^{1,2}$ \\ ${ }^{1}$ Nari Group Corporation/State Grid Electric Power Research Institute Nanjing 210003 China \\ ${ }^{2}$ Beijing Kedong Electric Power Control System Co., Ltd. Beijing 100194 China \\ ${ }^{3}$ North China Electric Power University, School of Economics and Management, Beijing 102206, China
}

\begin{abstract}
In the early stage of competitive trading of electric power market, the imperfection of market mechanism hinders the normal development of market competition, which leads to the defects of competition system and a large number of market transaction irregularities. The study of the irregularities of the market subject in the new background can provide a new strategy for the future power market. The study of the irregularities of the market subject in the new background can provide a new strategy for the future power market. In view of this, this paper first combed the analysis process of irregularities of whole process of electricity market trading. Then, the paper divides them from three time scales, namely, pre transaction, transaction and post transaction, and analyzes the three irregularities and reasons of the basic information accuracy and matching degree before transaction, the vicious bidding strategy in transaction, and the completion situation after the transaction. Finally, an index system of irregularities is proposed for the whole process of electricity market transaction, which will provide a useful reference for future effective supervision of market transactions, reduce the occurrence of irregularities and ensure the smooth development of market transactions.
\end{abstract}

\section{Introduction}

Let go of power sales market, study of market operating mainly for power generation side, the main problems of market operation is illegal and monopoly, the power plant violations declared price, don't follow the scheduling and abuse of market power, such as behavior, including the generation collusion is the most typical representative of irregularities ${ }^{[1-2]}$. At present, the market supervision index system ${ }^{[3-4]}$, which measures the utilization of power generation market, mainly includes the market supply and demand, market structure, bidding strategy, supplier status and transaction results. The electric power market has changed greatly after the sale of the electric side, and it pays more attention to market efficiency and risk control while balancing security and stability ${ }^{[5]}$. The role of market forces on the supply side unilateral steering on both sides of supply and demand, social capital can enter after sell electricity market, carry out the research of cooperative game mechanism about small sell electricity companies, aimed at improving small sell electricity companies profit ${ }^{[6]}$, but at the same time will bring the monopoly situation of the demand side. Literature ${ }^{[7]}$ analysed the foreign mature power market supervision means: information disclosure, fine, adjustment of price, modification of market rules and parameters, etc., for reference of China's electricity market. Among them, in order to improve the market efficiency, the effective information of market supervision is reasonably disclosed, including the basic information provided by the market subject and the transaction dispatching institution and the evaluation information of market regulators ${ }^{[8]}$. With the continuous improvement of the information level of the power industry, the power big data provides an important method for market operation monitoring. The research USES the data mining method to explore the potential correlation of market operation indicators to establish the risk warning system and market subject behavior analysis of the power grid company ${ }^{[9-10]}$.

\section{Design of Process of Analysis of Noncompliance in the Whole Process of Power Market Transaction}

\subsection{Analysis of the Whole Process of Violation in Trading in Power Market}

In the transaction of the main transaction analysis should follow the principle of comprehensiveness, the whole process of trading in the power market, the index system design includes the following aspects.

(1) Multi-agent: sales companies, power generation companies, power users.

SGEPRI-KJB-KJ(2016) 7436) Research on the operation risk analysis and support technology of electricity market in the interaction of supply and demand 
(2) Multi-dimensional: before the transaction, the transaction, after the transaction.
(3) Multi-target: a multi-objective comprehensive index system of safety, economy and high efficiency of electricity trading.

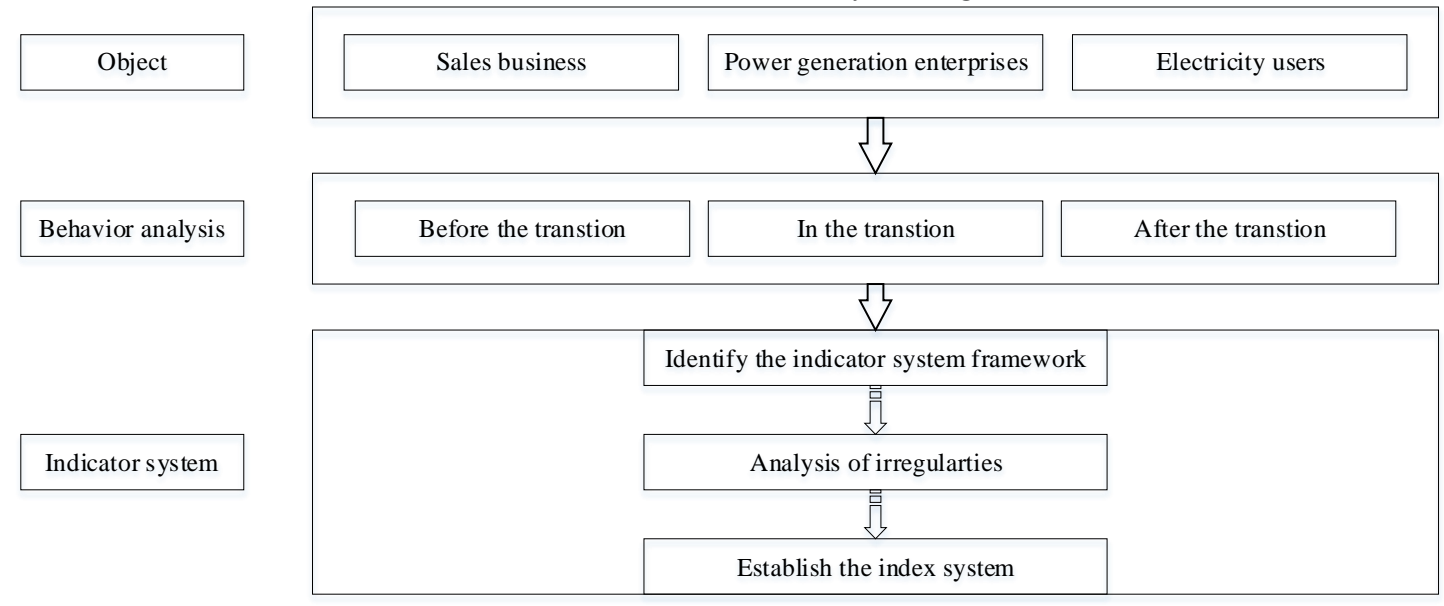

Figure 1. Analysis of Irregularities

\subsection{Design of Illegal Behavior Analysis Process}

In the process of designing a non-compliance analysis process, we should first make clear the various processes of power trading. At present, there are few researches on the analysis of irregularities in the whole process of transaction, so this paper analyzes the three dimensions of pre-transaction, post-transaction and post-transaction. Figure 2 details the analysis process of non-compliance.

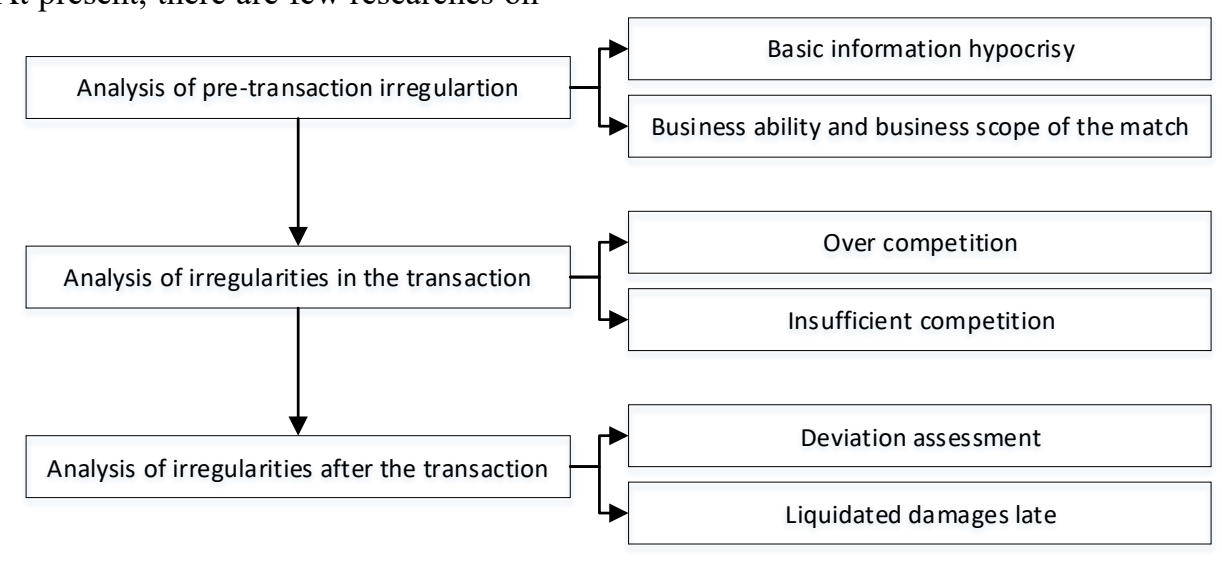

Figure 2. Irregularities analysis process

\subsubsection{Pre-transaction Non-compliance Analysis}

(1) The basic information is fictional

Due to the characteristics of China's power industry, the state-owned power generation side of the power generation is the mainstay of the system, the access control system is more stringent, the sales side to encourage social capital to open access to the regulation of the authenticity of their access information is more relaxed, so included in the credit rating in.

(2) The matching of business ability and business scope

In the third chapter of "Mid-term and long-term trading rules", when the market access and exit explicitly require the access of different transaction modes (direct transaction, inter-provincial cross-province transaction, contract power transfer transaction and auxiliary service transaction) Claim.

\subsubsection{Transactions In the Analysis of Irregularities}

Unlawful market conduct is difficult to identify and control in accordance with market rules and an effective set of methods must be put in place to identify, monitor and control it. The common behavior of the irregular market and the main features are shown in the following table. 
Table 1. Supplier's harmful bidding behavior and performance

\begin{tabular}{c|c|l}
\hline Type & Behavior & \multicolumn{1}{c}{ Behavioral characteristics } \\
\hline Over-competitive & $\begin{array}{c}\text { Competing to } \\
\text { bargain }\end{array}$ & \multicolumn{1}{c}{ Price long-term cost below } \\
\hline \multirow{2}{*}{$\begin{array}{c}\text { Insufficient } \\
\text { competition }\end{array}$} & Speculation & $\begin{array}{l}\text { Quotations for some periods are much higher than the average } \\
\text { price }\end{array}$ \\
\cline { 2 - 3 } & Profits pricing & $\begin{array}{l}\text { Some providers declare the price is much higher than other } \\
\text { competitors }\end{array}$ \\
\cline { 2 - 3 } & Alliance & All coalition members collectively reported high prices \\
\hline
\end{tabular}
caused by the deviation of electricity;

\subsubsection{Analysis of non-compliance after the transaction}

(1) deviation assessment of default behavior

This article defines the different principal violations as.

1) Power sales company does not have the load forecasting and other related professional software
2) Power generation enterprises have their power generation deviation due to their own operation or regulatory problems.

(2) breach of contract payment of late behavior

For the failure to pay liquidated damages, but also divided into the following situations.

Table 2. Supplier's harmful bidding behavior and performance

\begin{tabular}{c|c|c}
\hline Serial number & Arrears reason & Illegal definition \\
\hline 1 & $\begin{array}{c}\text { Business poor management, incapability to } \\
\text { pay liquidated damages }\end{array}$ & $\begin{array}{c}\text { Enterprise market access } \\
\text { violations }\end{array}$ \\
\hline 2 & $\begin{array}{c}\text { companies poor operating conditions that } \\
\text { year, incapable of paying liquidated damages }\end{array}$ & No violation, business problems \\
\hline 3 & default in arrears & Violation \\
\hline
\end{tabular}

\section{Market players in the transaction identification of violations}

\subsection{Analysis of the Whole Process of Violation in Trading in Power Market}

Faced with a number of uncertainties and complex interlacing environments, participants in the electricity market, starting from their own trading motivations, repeatedly play games and repeatedly market transactions to try their best to maximize their remuneration. Therefore, some understanding of the game approach is based on individual experience. All participants form their own rules of action and decision making based on their knowledge of the rules of action of other individuals. The decision-making process of the power market main body that produces the irregular behavior is as follows.

\subsection{Analysis of Multi - subject Violation}

\subsubsection{Analysis of Non - compliance of Power Generation Enterprises}

In the power market, there are some power companies that can not conduct transactions in violation of market rules. There are also some potential irregularities that are not identified by the rules, such as conspiring to raise electricity prices, conspiring to ensure transaction volume and freeing up high prices Harmful market behavior, undermines the competitiveness and effectiveness of the market, affects the optimal allocation of limited resources, thereby undermining the efficiency of the electricity market.

Table 3. Identification of violation strategy of power generation enterprises

\begin{tabular}{ccc}
\hline \multicolumn{2}{c}{ Power Generation Strategy } & Manifestations \\
\hline $\begin{array}{c}\text { Extreme pricing } \\
\text { strategy }\end{array}$ & $\begin{array}{c}\text { Raise the price + make } \\
\text { sure the volume is sold }\end{array}$ & Most power generation companies also reported a uniform price \\
\hline $\begin{array}{c}\text { Gentle quotation } \\
\text { strategy }\end{array}$ & $\begin{array}{c}\text { Conspire to raise prices } \\
\text { Conspiracy to ensure the } \\
\text { turnover of electricity }\end{array}$ & $\begin{array}{c}\text { Conspiracy Power the market capacity of generating companies offer } \\
\text { slightly higher than the historical clearing price, lower than the feed-in } \\
\text { tariff. }\end{array}$ \\
\cline { 2 - 3 } & Free ride & Some tenders offer much higher than the clearing price \\
\hline
\end{tabular}




\subsubsection{Analysis of Violation of Sales Companies}

The focus of the new round of electricity reform is to open the sales side, in which sales companies become emerging market players, but also the focus of supervisors in power market regulators, power sales companies to participate in the electricity market, its main market behavior is with the power generation companies Transaction, so the analysis of noncompliance of the sales of power companies, the focus should be on their participation in the power market transactions, the existence of abuse of market power bidding.

Table 4. Identification of violation strategy of sell electricity company

\begin{tabular}{ccc}
\hline \multicolumn{2}{c}{ Sales company strategy } & Manifestations \\
\hline $\begin{array}{c}\text { Extreme pricing } \\
\text { strategy }\end{array}$ & $\begin{array}{c}\text { Reduce the price }+ \\
\text { ensure the volume of } \\
\text { electricity }\end{array}$ & Most power sales companies also reported a uniform price \\
\hline \multirow{2}{*}{$\begin{array}{c}\text { Gentle quotation } \\
\text { strategy }\end{array}$} & Lower the price & $\begin{array}{c}\text { The selling company, which accounts for half of the market } \\
\text { share, is slightly lower than the historical clearing price }\end{array}$ \\
\cline { 2 - 3 } & $\begin{array}{c}\text { Ensure that the volume } \\
\text { of electricity }\end{array}$ & $\begin{array}{c}\text { The conspiracy to sell electricity company quoted a high } \\
\text { degree of similarity, and close to the historical clearing price }\end{array}$ \\
\cline { 2 - 3 } & Free ride & Some tenders offer much higher than the clearing price \\
\hline
\end{tabular}

electricity volume settlement.

\subsubsection{Analysis of Power User Violation}

Electricity users in the market transactions and sales of similar companies, the difference is that the composition of the sale of electricity companies more obvious, mainly by the power generation companies or persons with energy industry background registration, and each of the different users are in different industries, the conspiracy may Compared with power generation companies and electricity users lower. The occurrence of non-compliance focused on the issue of post-transaction

\section{Design of Non-compliance Indicator System}

Different market players in the transaction roughly similar violations, this paper presents a set of indicators of the power market players behavior violations, as shown in the following table.

Table 5. The indicator system of market subject irregularity

\begin{tabular}{|c|c|c|c|c|c|}
\hline & $\begin{array}{l}\text { A level of } \\
\text { indicators }\end{array}$ & & $\begin{array}{l}\text { Secondary } \\
\text { indicators }\end{array}$ & & Three indicators \\
\hline \multirow{9}{*}{ A1 } & \multirow{9}{*}{ Market behavior } & \multirow{2}{*}{ A11 } & \multirow{2}{*}{ Market power } & A111 & Market supply and demand ratio \\
\hline & & & & A112 & Declare power market share \\
\hline & & \multirow{4}{*}{ A12 } & \multirow{4}{*}{ Price strategy } & A121 & Price security \\
\hline & & & & A122 & Price comparison \\
\hline & & & & A123 & Retention ratio \\
\hline & & & & A124 & Price consistency \\
\hline & & \multirow{3}{*}{ A13 } & \multirow{3}{*}{ excess income } & A131 & Low winning rate \\
\hline & & & & A132 & High bid rate \\
\hline & & & & A133 & Bidding success \\
\hline
\end{tabular}

Market power is to determine whether the main transaction has the ability to default on quotations. The power generation side of the power industry has the characteristics of a monopoly, the sale side may be a competitive market or monopoly market, it is generally the market power.

1) market supply and demand ratio

$$
x_{0}=\frac{\sum_{i=0}^{n} S_{i}}{\sum_{i=0}^{j} D_{j}} \times 100 \%
$$

Where, $x_{0}$ is the market supply-demand ratio; $S_{i}$ is the ith power generation enterprise in the market; $D_{j}$ is the jth power purchase enterprise in the market.

2) Declare the electricity market share
(2)

In the formula, $x_{1 i}$ is the declared electricity percentage of the ith enterprise; $S_{i}$ is the declared electricity of the ith power generation enterprise.

(2) quotation strategy index analysis

The quotation strategy is to identify the subjective intention of the main body of the market transaction, and it can obtain high returns through different strategies.

1) quote security

$$
x_{2 i}=\frac{P_{v i}-E_{m}}{E_{m}} \times 100 \%
$$

Where $x_{2 i}$ is the quoted security of the i-th firm; $P_{a i}$ is the weighted average declared price of the i-th firm, 
weighted by the multiple quotations in accordance with the declared power of each segment as weights; $E_{m}$ is the expectation of the marginal price of the market, The marginal price of historical trading is calculated.

2) Price comparison

$$
x_{3 i}=\frac{P_{v i}}{\left(\sum_{i=\mathrm{n}}^{n} P_{v i}\right) / n} \times 100 \%
$$

Where, $x_{3 i}$ is the ith company's price comparison. The relative proportion of quotations reflects the difference between a quotation of an enterprise and the average price of this quotation.

3) retention ratio

After the seller and the seller participate in the quotation, there will be some reserved space for purchasing electricity without participating in the declaration. The holding ratio of the seller and the seller can be expressed as.

$$
x_{4 i}=\frac{s_{m i}-s_{i}}{s_{m i}} \times 100 \%
$$

In the formula, $x_{4 i}$ is the holding ratio of the $\mathrm{i}$-th enterprise; $S_{m i}$ is the largest generating capacity of the ith enterprise. Retention ratio with the market supply and demand than consider.

4) Price consistency

$$
x_{5 i}=\frac{s_{s}}{\sum_{i=n}^{n} s_{i}} \times 100 \%
$$

In the formula, $x_{5 i}$ is the consistency of quoted price of the i-th firm; $S_{s}$ for the quote similarity in $\chi \%$, and the $\chi$ value depends on the market transactions, where $0.5 \%$ is chosen.

(3) excess return

1) low price successful rate

$$
x_{6 i}=\frac{s_{l i}}{s_{i}} \times 100 \%
$$

In the formula, $x_{6 i}$ is the low bidding rate of the ith enterprise; the quoted price for the ith enterprise is lower than the lowest value of the past clearing price in the previous year and the bid is successful.

2) high bidding rate

$$
x_{7 i}=\frac{s_{k i}}{s_{i}} \times 100 \%
$$

In the formula, $x_{7 i}$ is the i-th company's high bidding rate; $\mathrm{S}_{h i}$ is the i-th company's bid is higher than the highest value of the previous year's clearing price and wins the bid.

3) quote the degree of success

$$
x_{8 i}=\frac{s_{d i}}{s_{i}} \times 100 \%
$$

In the formula, $x_{\mathbf{8} i}$ is the successful degree of quoted price of the ith enterprise; $S_{d i}$ is the percentage of declared electricity transaction volume of the ith enterprise; $S_{v}$ is the percentage of the average declared electricity volume of the market.

\section{Conclusion}

This article defines the typical default behaviors that may occur in the whole process of electricity market transactions, and separately from the three time scales before, during the transaction and after the transaction, and analyzes the fictitious information, the assets and the business conditions Mismatch, the main market manipulation of market prices in the transaction, multiparty implementation of "conspiracy", deviation settlement after the transaction, breach of contract damages and other irregularities were analyzed. To explore the typical methods of identification of irregularities, including unilateral conspiracy of the market players, free-rider and sale of the conspiracy behavior of both parties, to provide a definition of the indicators for the construction of electricity market assessment criteria.

\section{References}

1. Li Ruiqing, Liu Dunan, He Guangyu, etc. Power Market Operations Regulatory Information System [J]. Automation of Electric Power Systems, 2004,28 (14): 18-22.

2. Zhang Lizi, Zhang Ji, Cheng Yu. Improvement of collusion premium and conspiracy behavior in power market $[\mathrm{J}]$. Power System Technology, 2006,30 (24): 61-67.

3. Liu Dunnan, Li Ruiqing, Chen Xueqing, etc. Industry market supervision index and market evaluation system [J]. Automation of Electric Power Systems, 2004, 28 (9): 16-21.

4. Liu Dunnan, Chen Xueqing, He Guangyu, etc. Analysis and countermeasures of supplier bidding in electric power market [J] .Automation of Electric Power Systems, 2005, 29 (6): 24-28.

5. Xia Qing, Li Canbing, Jiang Jianjian etc. Regulatory methods, indicators and means of foreign electricity markets [J]. Power System Technology, 2003, 27 (3): $1-4$.

6. Li Chanbing, Kang Chongqing, Jiang Jianjian etc. Information disclosure and market evaluation in electricity market regulation $[\mathrm{J}]$. Automation of Electric Power Systems, 2003, 27 (21): 1-6.

7. Ma Li, Huang Liming, Xue Song, etc. Key issues on the orderly operation of China's new round of power market reform pilot $[\mathrm{J}]$. China Electric Power, 2017,50 (4): 17-22.

8. Li Xiaolan, Tian Xiaolei, Ni Zhijian, etc. Operation monitoring and analysis based on big data mining [J]. Northeast Electric Power Technology, 2016, 37 (3): 38-42.

9. Liu Fengkui. Detection and analysis of outliers of power big data based on density peak clustering algorithm [D]. China Electric Power Research Institute, 2017.

10. Tan Zhongfu, Wang Guan, Li Peng, etc. Study on the cooperative game between dealers and sellers in 
the market environment [J]. China Electric Power, 2017, 50 (4): 45-51 